\title{
Mechanisms and Stability of Arsenic Fixation by Biogenic Sulfides During In Situ Groundwater Remediation
}

\author{
Dimitri Vlassopoulos ${ }^{1}$, JAMES REDWINE ${ }^{1}$, MinG- \\ KUO LEE ${ }^{2} \&$ PEGGY A. O'DAY ${ }^{3}$ \\ ${ }^{1}$ Anchor QEA LLC, dvlassopoulos@anchorqea.com \\ ${ }^{2}$ Auburn University, Alabama \\ ${ }^{3}$ University of California, Merced
}

Successful in situ remediation of an arsenic plume in a surficial sand aquifer was achieved by injection of a degradable organic carbon substrate (molasses) and ferrous sulfate solution to induce formation of biogenic sulfides. Native sulfate-reducing bacteria transformed sulfate to sulfide which combined with iron and trace elements in groundwater to form biogenic sulfide precipitates. Three weeks after injection, arsenic concentrations had decreased below preinjection levels at 12 of 17 groundwater monitoring locations and was sustained at most of the locations a year later. On a site-wide basis, arsenic concentrations in groundwater were statistically lower after the treatment.

Biogenic precipitates were collected on quartz sand packs suspended in monitoring wells within the treatment zone, and characterized by XRF, XRD, EMPA, and X-ray absorption spectroscopy (XANES and EXAFS) to investgate arsenic uptake mechanisms. Pyrite was the main crystalline phase idenitified by XRD and microprobe analyses showed micronsized pyrite frambioids with variable arsenic content (up to 1 $w t \%)$ indicative of arsenian pyrite. Arsenic K-edge XANES spectra of the same samples, however, revealed As-S and $\mathrm{As}(\mathrm{V})-\mathrm{O}$ as the dominant arsenic coordination environments. Least squares fits to EXAFS spectra further refined the As-S component to be realgar-like $\left(\mathrm{As}_{4} \mathrm{~S}_{4}\right)$, with minor fractions of orpiment $\left(\mathrm{As}_{2} \mathrm{~S}_{3}\right)$ and enargite $\left(\mathrm{Cu}_{3} \mathrm{AsS}_{4}\right)$. The coexistence of realgar with pyrite in shallow groundwaters has been previously observed and explained on thermodynamic grounds, but our results indicate that the biogenic arsenian pyrite contains nanoscale realgar-like domains that repesent a quantitatively important pool of arsenic. Sequential extactions and column leaching studies were also performed to assess long-term stability of the sequestered arsenic. Selective sequential extraction of the biogenic precipitates showed that most of the arsenic was released in the oxidizable fraction, consistent with its uptake in sulfide phases. Effluent arsenic concentrations in column leaching tests of the precipitates with site groundwater were less than $10 \mu \mathrm{g} / \mathrm{L}$ for up to 1,000 pore volumes, suggesting that the neoformed arsenicsequestering phases will remain stable in the subsurface on multi-decadal to century timescales. 